\title{
PERCEPÇÕES SOBRE A VIOLÊNCIA NO CENÁRIO DE UMA UNIDADE DE SAÚDE DA FAMÍLIA
}

Maria de Lourdes Denardin Budó1, Maria Denise Schimith², Dalva Cezar Silva ${ }^{3}$, Silvana de Oliveira Silva ${ }^{4}$, Adonias Santos da Rosa ${ }^{5}$, Pâmela Batista de Almeida ${ }^{6}$

RESUMO: Objetivou-se conhecer o contexto da violência no cenário de uma Unidade de Saúde da Família do sul do Brasil. Trata-se de pesquisa qualitativa realizada em 2008 e na qual se utilizou para a coleta de dados a estimativa rápida participativa. Participaram 19 informantes-chave, sendo seis moradores líderes de comunidade, seis agentes comunitários de saúde e sete entre demais integrantes da equipe de saúde. Os dados foram submetidos à análise temática de conteúdo, produzindo-se três categorias: policiamento como fator de segurança; a violência influenciada pelo contexto social e a banalização da violência. Os resultados revelam um entendimento complexo acerca da violência, no entanto, a sua banalização pode ser verificada. A Enfermagem, junto à equipe de saúde, pode contribuir para a redução dos índices de violência, colocando-se na posição de mediadora na construção de uma rede social que identifique, integre, articule e promova ações capazes de melhorar as condições de vida da comunidade.

PALAVRAS-CHAVE: Violência; Programa saúde da família; Enfermagem.

\section{PERCEPTIONS OF VIOLENCE IN A FAMILY HEALTH UNIT SETTING}

ABSTRACT: The objective was to learn about the context of violence in the setting of a Family Health Unit in the south of Brazil, through qualitative research carried out in 2008. Participatory rapid appraisal was used for data collection. Nineteen key participants were involved, these being six community leaders, six community health assistants, and seven other members of the health team. The data was submitted to thematic content analysis, which produced three categories: policing as a factor for security; violence influenced by social context; and the banalization of violence. The results reveal a complex understanding of violence although its banalization may be verified. Nursing, along with the health team, can contribute to the reduction of levels of violence, putting itself in the position of mediator in the construction of a social network which identifies, incorporates, articulates and promotes actions which are capable of improving the life of the community.

KEYWORDS: Violence; Family health program; Nursing.

\section{PERCEPCIONES SOBRE LA VIOLENCIA EN UNA UNIDAD DE SALUD DE LA FAMILIA}

RESUMEN: El objetivo del estudio fue conocer el contexto de la violencia en una Unidad de Salud de la Familia del sur de Brasil. Es una investigación cualitativa realizada en 2008 y en la cual se utilizó para recoger los datos la estimativa rápida participativa. Participaron 19 informantes clave, siendo que seis eran líderes de la comunidad, seis agentes comunitarios de salud y siete integrantes del equipo de salud. Los datos fueron sometidos al análisis temático de contenido, produciéndose tres categorías: Vigilancia como factor de seguridad; La violencia influenciada por el contexto social y La banalización de la violencia. Los resultados revelan un entendimiento complejo acerca de la violencia, sin embargo su banalización puede ser verificada. La enfermería, junto al equipo de salud, puede contribuir para la reducción de los índices de violencia, poniéndose en la posición de mediadora en la construcción de una red social que identifique, integre, articule y promueva acciones para mejorar las condiciones de vida de la comunidad.

PALABRAS-CLAVE: Violencia; Programa Salud de la Familia; Enfermería.

${ }^{1}$ Enfermeira. Doutora em Enfermagem. Professora do Departamento de Enfermagem e do Programa de Pós-Graduação em Enfermagem da Universidade Federal de Santa Maria - PPGEnf UFSM. Vice líder do Grupo de Pesquisa Cuidado, Saúde e Enfermagem.

${ }^{2}$ Enfermeira. Mestre em Enfermagem. Doutoranda em Enfermagem pelo Doutorado Interinstitucional Novas Fronteiras UNIFESP/ UFSM. Professora do Departamento de Enfermagem da UFSM. Membro do Grupo de Pesquisa Cuidado, Saúde e Enfermagem.

${ }^{3}$ Enfermeira. Especialista em Saúde Pública. Mestranda em Enfermagem pelo PPGEnf UFSM. Funcionária Técnico-administrativa do Departamento de Enfermagem da UFSM. Membro do Grupo de Pesquisa Cuidado, Saúde e Enfermagem.

${ }^{4}$ Enfermeira.Mestre em Enfermagem. Coordenadora do Curso de Graduação em Enfermagem da Universidade Regional Integrada do Alto Uruguai e das Missões, Campus Santiago.

${ }^{5}$ Acadêmico de Enfermagem da UFSM.

${ }^{6}$ Enfermeira. Mestranda em Enfermagem pelo PPGenf UFSM.

Autor correspondente:

Maria de Lourdes Denardin Budó

Recebido: $11 / 12 / 2011$

Universidade Federal de Santa Maria

Aprovado: 31/01/2012

Av. Roraima, 1000 - 97105-900 - Santa Maria-RS-Brasil

E-mail: lourdesdenardin@gmail.com 


\section{INTRODUÇÃO}

A violência, nas suas diversas formas, juntamente aos acidentes e às doenças crônicas degenerativas, representa um novo perfil no quadro mundial dos problemas de saúde ${ }^{(1)}$.

Constata-se que o perfil de morbidade e mortalidade da população brasileira é influenciado pelas condições, situações e estilo de vida. Além disso, revela-se aumento da morbimortalidade oriundo da violência ${ }^{(2)}$.

O termo violência origina-se da palavra latina vis, que significa força. Suas características são pontuadas como oriundas dos conflitos de autoridades, das lutas pelo poder, da vontade do domínio, de posse e de aniquilamento do outro ou de seus bens. Na visão popular, a representação dominante de violência é a do crime e da delinquência, enquanto na visão erudita de uma linha específica de pensamento a violência está arraigada nas relações sociais e, principalmente, é construída no interior da consciência do sujeito, como revolta frente à sociedade e como um meio para atingir fins objetivos ${ }^{(1)}$.

$\mathrm{Na}$ área da saúde, a temática da violência tem sido estudada em decorrência do problema que ela representa para a qualidade de vida das pessoas, da família e da comunidade, pois acarreta problemas físicos, psíquicos, morais e sociais que necessitam de atenção e cuidado nos serviços de saúde ${ }^{(1-4)}$. A violência apresenta variações históricas, culturais, marcadas por percepções, sensibilidades e concepções diferentes ${ }^{(3)}$, abrangendo os campos sociocultural e político, além do âmbito da saúde ${ }^{(4)}$, devendo ser encarada como um objeto da intersetorialidade ${ }^{(2)}$.

Dessa forma, conhecer as representações e práticas populares em relação à violência é relevante para a construção de propostas que contribuam para diminuir sua ocorrência e propor ações de prevenção, uma vez que cada grupo social pensa e vivencia a violência a partir de seu contexto social.

$\mathrm{O}$ respeito e a valorização das diferenças dos sujeitos permitem uma melhor aproximação na conformação de um território a ser atendido e o reconhecimento das condições de vida da população aí residente, de suas necessidades e prioridades. Nesse sentido, é necessário olhar como as pessoas vivem e quais os recursos de que dispõem para atender suas necessidades e expectativas no cuidado à saúde, pois se entende que as ações em saúde não devem se restringir somente às necessidades dos indivíduos, identificadas por critérios técnicos, mas devem considerar percepções, valores, sentimentos, costumes, rituais, instituições e objetos que rodeiam a vida das pessoas $^{(5)}$. Nessa conjuntura, o Diagnóstico Comunitário de Saúde surge como uma proposta oportuna para identificar os problemas, as necessidades, os recursos de uma comunidade, constituindo-se como a primeira etapa do planejamento em saúde.

Assim, este artigo é fruto de um dos achados do Diagnóstico Comunitário realizado em uma Unidade Saúde da Família (USF) de um município da região central do Estado do Rio Grande do Sul e tem por objetivo apresentar as percepções de usuários e profissionais de saúde acerca da violência no território de uma USF.

\section{MÉTODO}

Trata-se de uma pesquisa de campo, qualitativa, descritiva, realizada na região de abrangência de uma USF localizada em um município do sul do Brasil. A USF abriga duas equipes de Estratégia Saúde da Família (ESF), as quais abrangem seis microáreas, em cada área de atuação. Neste estudo, foram utilizados os dados de duas microáreas, escolhidas por apresentar diferenças socioeconômicas e culturais marcantes, representando a heterogeneidade do território, uma se localiza nas proximidades da USF e outra distante.

Utilizou-se, como método de coleta de dados, a Estimativa Rápida Participativa (ERP), que comporta registros existentes de fontes primárias e secundárias, observação de campo e entrevistas com informanteschave, selecionados intencionalmente como pessoas de referência da comunidade. A ERP proporcionou a identificação das necessidades de saúde dos distintos grupos que constituem a população, uma vez que esse método se fundamenta na procura de dados importantes relativos às verdadeiras condições locais, possibilitando o envolvimento da própria comunidade na busca de estratégias eficazes para a resolução de seus problemas ${ }^{(6)}$. Nesse sentido, a maior contribuição desse método reside no fato dele evidenciar os problemas que afetam a população e seus determinantes sociais, econômicos e ambientais ${ }^{(7)}$.

A coleta de dados ocorreu durante o primeiro semestre de 2008. Foram realizadas entrevistas com 19 informantes-chave, sendo seis moradores líderes de comunidade, seis Agentes Comunitários de Saúde (ACS) e sete dos demais, integrantes das duas equipes da USF. Para resguardar a identidade dos participantes, eles foram identificados com código composto por uma ou duas letras e um número. As letras MO representam 
os moradores; EA representam os Agentes Comunitários de Saúde; e E representa os demais profissionais da equipe de saúde da área pesquisada; o número subsequente à letra identifica a ordem da realização das entrevistas. Os dados foram submetidos à análise temática de conteúdo ${ }^{(6)}$.

O estudo foi aprovado pelo Comitê de Ética em Pesquisa da instituição de referência, com o Certificado de Apresentação para Apreciação Ética (CAEE) número 0088.0.243.000-08. No decorrer de todo o processo respeitaram-se as normas éticas da Resolução 196/96 sobre a pesquisa com seres humanos ${ }^{(8)}$.

\section{RESULTADOS}

Apresentam-se, a seguir, as três categorias obtidas a partir dos procedimentos analíticos: o policiamento como fator de segurança, a violência influenciada pelo contexto social e a banalização da violência.

$\mathrm{Na}$ categoria o policiamento como fator de segurança, foi marcante a relação de violência com a criminalidade em todo o território pesquisado, sendo evidenciada a importância da presença do policiamento. A criminalidade é considerada uma característica no cenário comunitário do estudo e que é expressa nas informações relatadas pelos informantes-chave.

$\mathrm{Na}$ área que recebeu um posto policial, os moradores confirmaram que a presença de policiamento contribuiu para amenizar o problema de segurança na comunidade.

A segurança na comunidade é um problema bastante sério. Depois do policiamento deu uma amenizada. (M05)

É um dos melhores bairros que tem, depois que veio esse policiamento para cá. (M06)

Por tratar-se de uma área com indicadores socioeconômicos mais baixos, ela apresenta uma série de dificuldades nas condições de vida da população, mas a presença do policiamento, segundo os informantes, ajudou nas questões relacionadas à segurança, sendo este considerado um fator que qualificou a vida na área. Destaca-se que, para os moradores, a violência é influenciada pela falta ou pouca segurança local.

Da mesma maneira, os ACS e demais integrantes da equipe de saúde da ESF referiram que o aumento do efetivo de policiais poderia auxiliar na manutenção da segurança na região em que foi fechado o posto policial. Assim, aumentar o efetivo da polícia militar foi apontada como uma possibilidade para amenizar a situação de violência:

Acho que se eles colocassem aqui um tipo de vigilância maior por parte da brigada, policiamento que passasse de hora em hora, diminuiria bastante. (EA1)

Talvez se tivesse mais policiamento, reforço de pessoal efetivo de policiais na rua. (EA3)

Também na região próxima à USF, em que ocorreu o fechamento do posto policial, foi apontado pela equipe de saúde que a segurança diminuiu:

Antes a gente tinha a Brigada que protegia bastante a Unidade de Saúde e o colégio. (E07)

Eu acho que [a segurança] diminuiu bastante porque tinha um posto da brigada militar aqui e foi desativado, porque foi ativado outro, em outra região. (E02)

Além do pouco policiamento, passou a ser marcante nas falas dos ACS e dos demais profissionais a repercussão do fechamento e desativação do posto policial em uma das áreas. A retirada do posto policial é considerada um aspecto relevante no aumento da delinquência, crimes, vandalismo, arrombamento, entre outras questões relatadas pelos entrevistados:

Aqui tem muito arrombamento de casas e assaltos. (EA1)

Durante a noite, há um guardinha que é pago, então acaba não tendo muito roubo nesse período. Logo que saiu o posto [policial] começou a surgir vandalismo em todos os lugares; até o mercado aqui já foi assaltado umas duas ou três vezes. (EA3)

Não temos nenhuma segurança! Antes tinha uns "brigadianos", agora não tem mais. Eu acho que está fazendo falta. O pessoal reclama, de noite está perigoso. (E05)

No momento que saiu daqui, a Unidade [de Saúde] teve vandalismo, várias vezes. Deixou o lugar desprotegido. Assim, à noite, tanto a creche como o colégio não têm segurança. (E07)

Assim, a desativação do policiamento na comu- 
nidade ocasionou, além do aumento dos casos de violência, o uso e tráfico de drogas:

A Segurança já foi melhor. Depois da desativação parcial da Unidade da Brigada Militar do Bairro houve um aumento dos casos de violência, gerados principalmente pela presença do consumo e tráfico de drogas na região. (E04)

Portanto, em virtude da falta de policiamento, a comunidade torna-se mais vulnerável à entrada e aumento do uso de drogas. Frente a essas questões, reporta-se para uma outra categoria presente nos depoimentos, $a$ violência influenciada pelo contexto social.

Os profissionais da saúde das equipes da ESF reconhecem que a problemática da droga exerce influência nas questões relacionadas à violência e problemas de saúde da população. Os profissionais vivenciam os relatos dos moradores quanto ao problema do uso de drogas nas famílias, bem como o impacto desse fato na comunidade:

A segurança piorou na comunidade depois [...] da chegada do crack na região, há aproximadamente um ano. (E6)

Aqui na localidade tem duas bocas de fumo bem fortes. (E07)

Vários são os relatos de moradores quanto à presença de substâncias psicoativas na família, vizinhos, arredores da escola, gerando uma insegurança, temor dos pais e de toda a comunidade. (E04)

A presença da droga na comunidade favorece a realização de atos criminosos, além de representar um problema para os moradores ao atingir a faixa etária economicamente ativa, segundo os informantes:

[...] tem muito uso de drogas, muito "bolinho" de consumo de drogas nas esquinas. Se drogam e vão roubar, assaltar. (EA1)

Tem problemas também com drogas, com adolescentes, jovens, crianças e adultos. (M05)

Verifica-se que, para os sujeitos da pesquisa, a presença do uso de drogas na comunidade repercute na segurança, pois potencializa a ocorrência de situações violentas. Além disso, a dependência química pode associar-se a questões, tais como, precárias condições financeiras, de saúde e estruturais da sociedade.

Outro fator referido na fala de um profissional da equipe de saúde como problema social, que pode potencializar a insegurança, é o ócio e/ou a falta de trabalho formal:

Quanto ao fator segurança, o problema está [...] na falta de emprego. (E5)

Também é observada, na comunidade, a presença de catadores, trabalhadores informais e trabalho de adolescentes, para ajuda aos pais. Os moradores consideram que a falta de trabalho para os jovens pode favorecer a realização de atos de violência.

Os fatores que interferem na segurança é a ociosidade da moçada. Tem muita gurizada sem emprego [...]. (MO1)

\section{[...] para ter segurança tem que ter trabalho. (M02)}

Além da preocupação com a população jovem da comunidade, que se encontra sem emprego, a questão socioeconômica relacionada com a violência é também evidenciada por um morador como resultante da formação e aumento dos moradores da comunidade atendida pela ESF:

O aumento da população, e com as invasões, trouxe insegurança [...]. (M01)

Portanto, surge uma interface entre a questão socioeconômica, condições de vida e segurança dos sujeitos da comunidade, sendo o desemprego um fator importante que dificulta a melhoria dessas condições.

Foi também identificado pelos participantes desse estudo, que algumas situações de violência perpassam o cotidiano da comunidade e são consideradas normais. A partir disso, aborda-se a banalização da violência, a qual se encontra nos relatos a seguir. Estes pontuam a ocorrência de brigas, como desentendimentos pessoais causados por ciúmes entre vizinhos:

Existem desentendimentos entre os moradores. (M05)

Briga tem em toda parte, mas briga assim, de se machucar, não. (M02)

Os desentendimentos entre os moradores da comu- 
nidade, quando tem é, devido a ciúme um do outro. Além disso, também a [falta de] orientação dos pais com os filhos. (M06)

Constata-se que ocorre uma diferenciação e valorização da violência física. Além das brigas entre vizinhos, aparecem ainda, referências à violência familiar. A banalização da violência familiar foi descrita por um profissional da equipe de saúde, o qual relatou as diferenças entre as áreas estudadas:

Na sede, é mais calmo com relação à violência. Já na área mais distante, a gente ouve falar em violência. Existe [...], violência física familiar. Mas acho que não é um dos bairros mais violentos da cidade. (E03)

Percebe-se que a violência familiar e comunitária são banalizadas tanto pelos moradores como pelos profissionais da saúde. Para os moradores, a violência familiar é considerada como uma forma de orientação educacional dos pais com os filhos; já para a equipe, ela é identificada como uma maneira usada pelas famílias para a solução de alguns conflitos. Os ACS não fizeram referências a casos deste tipo de violência, mas reconhecem que há desentendimentos ocorridos entre os próprios moradores e que são marcados pela questão educacional e cultural:

Brigas é raro de acontecer, e se acontece é só entre eles ali mesmo. E, às vezes, nem ficamos sabendo. (EA3)

São bobagens assim, algum desentendimento, não tenho bem uma definição. Ter segurança também é uma questão de educação, tudo, também cultural. (EA1)

Portanto, algumas situações de violência podem ser percebidas como questões naturais na comunidade, influenciadas pelo contexto social ou pela ausência de policiamento.

\section{DISCUSSÃO}

As pessoas entrevistadas afirmam que a presença do policiamento é um fator de proteção, estando esta percepção ligada à concepção de segurança e à repressão do Estado. Essa posição converge com o conceito da violência entendida como sinônimo de delinquência e criminalidade ${ }^{(1)}$.

Por meio dos relatos, evidencia-se o período noturno como o mais preocupante para a segurança da população, pois, segundo os entrevistados, é quando costumam ocorrer as situações de violência. Identificam-se a escola, a creche e a Unidade de Saúde como as principais instituições que são alvo de vândalos, pois elas não contam com a presença de um policial ou guarda de segurança. Para os participantes da pesquisa, a presença do policial é determinante para a diminuição de assaltos, arrombamentos e depredação de órgãos públicos, essenciais à comunidade. Supõe-se, portanto, que há a necessidade de repressão do Estado para a não-ocorrência de violência, uma vez que, no entendimento dos entrevistados, a violência ocorre por falta de policiamento.

Comparando com outro estudo, realizado com a população residente da região de abrangência de uma USF da região central do Rio Grande do Sul, foi relevado que esta se sentia insegura para sair pelo bairro, independentemente de horário ou turno, sendo assim, uma questão específica local. Também, a falta de policiamento e o grande número de assaltos vivenciados com a família, vizinhos ou amigos próximos foram relatados como sendo os principais fatores causais de insegurança para os participantes da pesquisa ${ }^{(3)}$.

O tipo de violência que, neste momento, envolve o cenário brasileiro está posto nas bases econômicas. Ainda que permaneçam ocorrendo manifestações de violência já consideradas tradicionais, como agressões e abusos dentro da família, a violência de cunho coletivo que se expressa conforme as mudanças econômicas sofridas, em função do efeito da globalização, ganha grande relevância na sociedade. Dessa forma, a exploração da violência acaba por tornar-se de interesse econômico para alguns setores, como o de segurança privada ${ }^{(1)}$.

Assim, a violência pode estar relacionada ao desemprego vivenciado pela população da ESF, com a consequente desocupação dos jovens, sendo o trabalho considerado um fator que favorece a segurança. Em estudo realizado no pronto-socorro de um hospital universitário localizado no interior do estado foi constatado que as principais vítimas de acidentes e violência eram adultos jovens, com baixo nível de instrução e não-trabalhadores ${ }^{(9)}$.

Infere-se que a população estudada mostra a interrelação da situação socioeconômica, principalmente o desemprego, com os níveis de violência. Concordando, dessa forma, com estudos que apontam a vulnerabilidade social como causa de violência ${ }^{(10-11)}$. No entanto, pode-se relativizar este entendimento considerando que se estabelece uma relação dialética entre as condições de vida e violência, ora sendo causa, ora sendo 
consequência ${ }^{(12)}$.

O processo de globalização vem favorecendo o aumento e a exacerbação das diferenças econômicas e sociais que atingem, principalmente, os jovens da população brasileira $^{(1)}$. A violência, na chamada pós-modernidade, ocorre entre a legalidade e a ilegalidade da organização econômica. $\mathrm{O}$ tráfico de drogas, citado como marcante entre os jovens, nesta pesquisa, aparece como forte influência do contexto social ao qual os jovens pertencem. Esse contexto é permeado por desigualdades sociais, falta de oportunidade no mercado de trabalho e, portanto, falta de possibilidade de acesso ao consumo ${ }^{(1)}$.

Para o trabalhador de uma equipe da USF é importante reportar-se à concepção de saúde como processo individual, mas também coletivo, resultante das condições que partem do contexto social de vida das pessoas que pertencem a classes ou grupos sociais específicos. Esta compreensão é diferente do entendimento calcado na visão biomédica, em que saúde significa tão somente ausência de doença, sendo esta compreendida exclusivamente como um fenômeno individual, desconsiderando o caráter social dos indivíduos.

Nesse contexto, surge como uma das questões relevantes a serem observadas pelos profissionais da saúde as condições econômicas, bem como a estrutura educacional, que podem apontar para a vulnerabilidade social. Aqui, importa lembrar que o espaço de cuidado em saúde se inicia naquele em que a pessoa vive, ou seja, a família sendo considerada como o local onde se inicia e se irradia o cuidado. A formação cultural e histórica também influencia muitos aspectos da vida das pessoas - incluindo os profissionais - interferindo fortemente na saúde e sua assistência. Dessa forma, o agir profissional deve considerar que as crenças e valores da população sejam respeitados e considerados como fontes de aprendizado mútuo e de produção de conhecimento acadêmico e popular ${ }^{(13)}$.

Além disso, constata-se a importância da aproximação do trabalho dos profissionais de saúde com as redes sociais e seu contexto, para a realização de um adequado planejamento em saúde na área de abrangência de USF. Por meio dessa aproximação podem ser visualizadas as necessidades locais, bem como considerar a representação dos diversos grupos e as ofertas de ações ${ }^{(5)}$.

Ao conhecer as percepções da violência na comunidade estudada, identifica-se que é na família que ocorrem muitas das manifestações de violência. Essas manifestações foram relatadas pelos sujeitos de pesquisa com caráter banalizado, corriqueiro, consideradas como fatos comuns e previsíveis. A violência é também uma temática, de certa forma, banalizada na área da saúde, sendo um assunto ainda pouco explorado por essa área. Diante disso, revelou-se a pouca produção acadêmica, mas também se percebeu a preocupação do enfermeiro para com a temática ${ }^{(14)}$.

No entanto, profissionais da Enfermagem têm buscado estratégias para evitar a banalização da violência em seu cotidiano, sendo a problemática da violência familiar um desses desafios ${ }^{(3)}$, uma vez que são as mulheres, crianças e adolescentes as principais vítimas de agressões, nas diversas camadas sociais.

Outra situação relatada como frequente no estudo foi a violência física, a qual se caracterizou como brigas entre os membros da família, ou mesmo entre pessoas da comunidade, sendo considerada uma maneira de resolver conflitos causados por problemas familiares ou ciúmes entre vizinhos. Frente a isso, a interação entre fatores culturais, sociais e características individuais podem ser determinantes para a violência ${ }^{(13)}$, devendose repensar a garantia do respeito às pessoas e do seu reconhecimento como cidadãs ${ }^{(15)}$.

Diante disso, cabe aos profissionais de saúde, inseridos no contexto social em que trabalham, observar e agir em prol do respeito aos direitos da comunidade assistida, bem como repensar o planejamento de suas ações pautado nos instrumentos básicos de Enfermagem, nas políticas públicas de saúde e na legislação vigente, o que é fundamental para a proteção das vítimas e prevenção de agravos futuros ${ }^{(16)}$.

Além da violência familiar, também são enfatizadas como expressões da violência que se relacionam com a saúde, as violências estrutural e a institucional. A estrutural se caracteriza por tornar os indivíduos mais vulneráveis, pois incide sobre as condições de vida a partir de decisões histórico-econômicas e sociais, enquanto a institucional relaciona-se aos aspectos de entidades com as pessoas, como dificuldades no acesso, discriminação, burocracia excessiva, falta de pessoal para atendimento ${ }^{(1)}$.

Todas essas questões levam a se pensar na importância da equipe de saúde em trabalhar com a comunidade sobre a prevenção da violência por meio da aproximação de saberes, já que a violência familiar foi apresentada como uma prática banalizada na comunidade assistida pela USF. É a partir das exigências, padrões e permissões de determinada época e local que o modelo de relação intrafamiliar é socialmente construído ${ }^{(17)}$, e isso precisa ser conhecido pelo profissional de saúde.

Visando à desnaturalização da violência, profissionais de uma Unidade Básica de Saúde de Porto Alegre 
propõem como estratégia a veiculação do tema na mídia. Para os profissionais participantes dessa pesquisa foram considerados necessários investimentos na prevenção de casos, bem como maior articulação da rede de assistência à violência, qualificação das equipes de saúde para a detecção e atendimento do problema, e maior comprometimento dos profissionais com a resolução das situações de violência ${ }^{(3)}$. Nesse sentido, a ESF, por meio das Unidades Básicas de Saúde, tem importante papel na assistência e na prevenção da violência ${ }^{(18)}$.

\section{CONSIDERAÇÕES FINAIS}

Frente a esses dados, é possível inferir que o conceito de violência, para os pesquisados, está relacionado com a falta de segurança e a repressão pelo Estado, mas também ao contexto socioeconômico, destacando o desemprego, principalmente entre jovens. Revelou-se, portanto, uma visão ampliada e complexa do entendimento dos informantes-chave acerca da violência.

Os resultados indicam ainda a banalização da violência, a qual necessita primeiramente ser reconhecida como problema para depois ser abordada e enfrentada pela equipe de saúde. Essa abordagem pode ser realizada por meio de estudos de casos em reuniões de equipe, com o objetivo de buscar estratégias para a desnaturalização da violência familiar e da violência física, aprofundando o debate segundo os referenciais teóricos adequados para explicar o fenômeno para além das aparências, buscando a determinação mais central.

Diante dos dados apresentados, fica demonstrada a relevância da temática para o conhecimento dos profissionais de saúde, de modo que estejam atentos ao contexto social da população, uma vez que este aponta para a sua importância no planejamento em saúde que considere as necessidades e demandas da população, sendo calcado na intersetorialidade e na integralidade da atenção. Considerando que a ESF possibilita a integração e promove a organização de ações e serviços com a finalidade de enfrentar e resolver os problemas identificados na comunidade, acredita-se que esse nível de atenção básica constitui um dos meios pelo qual é possível potencializar as redes de atuação em prol da redução das violências e vulnerabilidades associadas.

Nessa conjuntura, a Enfermagem, apoiada nos saberes científicos e popular, poderá contribuir para a redução dos índices de violência colocandose na posição de mediadora na construção de uma rede social que identifique, integre, articule e promova ações governamentais e não governamentais capazes de melhorar as condições de vida de uma comunidade.

\section{REFERÊNCIAS}

1. Minayo MCS. Violência e saúde. Rio de Janeiro: FIOCRUZ; 2006.

2. Minayo MCS. A difícil e lenta entrada da violência na agenda do setor saúde. Cad. saude publica. 2004;20(3):511-9

3. Budó MLD, Mattioni FC, Machado TS, Ressel LB, Borges ZN. Concepções de violência e práticas de cuidado dos usuários da estratégia de saúde da família: uma perspectiva cultural. Texto contexto enferm. 2007;16(3):511-9.

4. Lima MADS, Rückert TR, Santos J LG, Colomé ICS, Acosta AM. Atendimento aos usuários em situação de violência: concepções dos profissionais de unidades básicas de saúde. Rev. gauch. enferm. 2009;30(4):625-32.

5. Budó MLD, Oliveira SG, Garcia RP, Simon BS, Schimith MD, Mattioni FC. Redes sociais e participação em uma comunidade referenciada a uma unidade de saúde da família. Rev. gauch. enferm. 2010;31(4):753-60.

6. Minayo MCS. O desafio do conhecimento: pesquisa qualitativa em saúde. $8^{\text {a }}$ ed. São Paulo: Hucitec; 2008.

7. Tancredi FB, Barrios SRL, Ferreira JHG. Planejamento em Saúde. [Internet] São Paulo: Ed. Faculdade de Saúde Pública da Uso; 1998. [acesso em 14 jan 2012]. Disponível: http://www.saude.mt.gov.br/adminpublicacao/arquivo/ Saude\%20\&\%20Cidadania\%20Volume02.pdf

8. Ministério da Saúde (BR). Conselho Nacional de Saúde. Diretrizes e normas regulamentadoras de pesquisa envolvendo seres humanos. Resolução n. 196, de 10 de outubro de 1996. Brasília; 1996.

9. Santos JLG, Garlet ER, Figueira Rb, Lima SBS, Prochnow AG. Acidentes e violências: caracterização dos atendimentos no pronto-socorro de um hospital universitário. Saúde soc. 2008;17(3):211-8.

10. Carmo CJ, Harada MJCS. Physical violence as educational practice. Rev. latino-am. enferm. 2006;14(6):849-56.

11. Coimbra JR, Alvares CE, Santos RV. Saúde, minorias 
e desigualdade: algumas teias de inter-relações, com ênfase nos povos indígenas do Brasil. Cienc. saude coletiva. 2000;5(1):125-32.

12. Minayo MCS, Souza ER. Violência e saúde como um campo interdisciplinar e de ação coletiva. Hist. cienc. saúde-Manguinhos. 1998;4(3):513-31.

13. Helmann CG. Cultura, saúde e doença. Porto Alegre: Artmed; 2003.

14. Budó MLD, Silva SO, Schimith DM, Rossato M, Rosa AS, Zimmermann LP, et al. Violência e vulnerabilidade: um panorama da produção científica. Revista saude. 2010;(36):15-22.

15. Frota MA; Nogueira J, Bezerra L, Lima P, Sousa Filho $\mathrm{O}$, Da Costa R. Percepção da criança da periferia de Fortaleza - Ceará acerca da violência. Cogitare enferm. 2010; 15(3):427-32.

16. Ferraz MIR, Lacerda M, Labronici L, Maftum M, Raimondo M. O cuidado de enfermagem a vítimas de violência doméstica. Cogitare enferm. 2009;14(4):755-9.

17. Ricas J, Donoso MTV, Gresta MLN. A violência na infância como uma questão cultural. Texto contexto enferm. 2006;15(1):151-4.

18. Rückert TR, Lima, MADS, Marques GQ, Garlet ER, Pereira WAP, Acosta AM. Assistência às vítimas de violência em unidades básicas de saúde na concepção de enfermeiras. Ciênc. cuid. saude. 2008;7(2):180-6. 